\title{
ICD, Mental Disorder and British Nosologists An assessment of the uniquely British contribution to psychiatric classification
}

\author{
MICHAEL SHEPHERD
}

During several recent international meetings on classification, there have been frequent references to national systems of classification developed and used in Europe, North America and many other countries. The UK has been notably absent from this list. As Professor Kendell, in his brief historical survey of the subject, points out: " British psychiatry does not have, and indeed never has had, any important diagnostic concepts of its own in the way that French, American, and Scandinavian psychiatry still do"'(Kendell, 1985).

\section{Historical background}

An early attempt to construct a British system of classification proposed in 1881 by the Statistical Committee of the Royal Medico-Psychological Association ended in abject failure. At the time, disregarding the flurry of elaborate classificatory schemes that accompanied the intense interest in theoretical models of mental disorders in the 19th century, most prominent British psychiatrists would have agreed with Henry Maudsley's comment that "classifications which pretend to go to the root of the matter go beyond what knowledge warrants and are radically faulty"' (Maudsley, 1879).

Perhaps, therefore, it is understandable that in 1904 Carl Jung should have written to Sigmund Freud, describing a psychiatrist of what he called "the English breed; knows how to catch salmon, sails and rows well, but has only a few barbaric notions of the psyche". This comment, however, merely exemplified the myopic vision characteristic of many psychoanalysts. An altogether broader perspective was provided by Adolf Meyer in his 1928 Maudsley lecture on British Influences in Psychiatry and Mental Hygiene (Meyer, 1933). Bringing to bear his unrivalled knowledge of the situation Meyer concluded:

"Somehow in earlier German and French thought the idea of development and evolution had played a role that proved somewhat premature in the hands of keen but not naturalistically trained thinkers. It was based on the principle of plausibility, over-elaborate and dialectical,

Based on a paper presented at a symposium of the Association of European Psychiatrists: The ICD-10: Psychiatric Classification on the Eve of the Third Millenium, Strasbourg, 1992. with the German temperament it was destined to become Naturphilosophie, i.e. a system-formation running ahead of the facts or of experimental proof. A peculiar conservatism gave British thought that sober and critical progression from Baconian principles to the Darwinian method of collecting data and seeking long-term developments, with that world-embracing range of inquiry possible only to the trained traveller and collector not only of dead museum specimens but also of events and their observations and records. It is easy to see how and with what results Germany and France developed their physiologists bent on physics and chemistry, and leaving man to the various philosophies and systems, and the English their physiology with physics and chemistry in natural biological settings. While German thought shaped its concept of parallelism as the way forward from Cartesian dualism, as a truce in matters of mind and matter and of man and nature, the thought of the English-speaking naturalist had in the biological principle a frame which did not make for a premature dogmatism and a premature rigidity, nor a demand for a pan-psychologizing."

Meyer acknowledged his debt to David Hume, Thomas Huxley, Hughlings Jackson, Charles Mercier and William McDougall in the construction of his common-sense psychiatry based on a psychobiology of human behaviour, which he called 'ergasia'. Thirty years later, Meyer's most eminent British pupil, Sir Aubrey Lewis, was to make a similar assessment of the characteristics of British psychiatry:

"On the whole", he wrote, "British psychiatrists since the time of Connolly have not been innovators. They have sifted the contributions of psychiatrists from other countries, accepting and modifying what seemed to them sound, and often applying pragmatic tests of truth. The outstanding names - Maudsley, Hack, Tuke, Bucknill, Forbes Winslow, Clouston, Mercier, Goodall, Mott, Tredgold, Mapother - are of men whose intellectual force is undisputed; but who did not give rise to new movements of thought.

"More recently ... the influence of Adolf Meyer has been . . . predominant. Indeed, it was easy for Britons to respond to this influence, because it represented no break with their own tradition, but rather an enlargement in the direction of therapy and in increased emphasis on accurate observation ... their outlook in practical matters of prognosis and treatment is empirical and catholic, and 
nonsectarian for the most part; they are fond of the clinical terra firma, and better pleased with a loose, inclusive framework of classification than with tight jacket of precise doctrine. Though they can hardly be considered true disciples and inheritors of Adolf Meyer's teaching, they are still recognizable beneficiaries" (Lewis, 1961).

The source of this contention is apparent in the longstanding debate about the classification of depression, and in the proceedings of a recently published Royal College of Psychiatrists' conference on concepts of mental disorder, where Meyer's psychobiological viewpoint dominated the issues of classification (Kerr \& McClelland, 1991).

\section{Development of the ICD}

With this background in mind it becomes easier to understand why, in sensu strictu, there is no British nosology. There are, however, British nosologists, and the readiness with which they became involved with the development of the International Classification of Diseases (ICD) can, I think, be related to the tradition of cautious empiricism and mistrust of theoretical elaboration which made them avoid 'schools' of psychiatry with their attendant systems of classification. In as much as ICD-10 (World Health Organization, 1992) represents the culmination of four decades of activity by the World Health Organization (WHO) it is relevant and instructive to recall their contribution.

\section{Early British involvement in ICD}

Official opinion in the UK was readily persuaded to adopt the 6th revision of ICD produced by the WHO shortly after its creation in 1948 . At that time, the UK was one of only five countries to have taken this step, the others being Finland, Peru, Thailand and New Zealand. The situation clearly called for a vigorous, practical initiative, which was provided in the late 1950's by the Mental Health Unit of the WHO, strongly supported by Sir Aubrey Lewis in his role as principal adviser on WHO mental health issues. Largely through his influence, a number of his professional associates in the UK were recruited to launch the series of programmes necessary to bring the topic to the forefront of attention in the international community. Among them I would make particular mention of Erwin Stengel, John Cooper, Robert Kendell, John Wing, Michael Rutter, Eileen Brooke and Kenneth Rawnsley.

The first step was taken by Erwin Stengel who cleared the ground in his survey of existing classificatory systems (Stengel, 1959), which he called a 'Tower of Babel'. This review contained two important recommendations: firstly, since the widespread use of diagnostic terms with aetiological implications impeded agreement on a common nomenclature, there should be a set of neutral, operational definitions which were primarily descriptive; and secondly, such definitions should accompany all future revisions of the ICD in the form of a glossary.

Shortly after the appearance of Stengel's report, the first WHO Scientific Group on Mental Health Research formally recommended the development of an internationally acceptable classification of mental disorders, including the preparation of glossaries, and it was decided to try to produce an international glossary in time to accompany ICD-8. As an interim measure, the UK accepted an invitation to produce a national glossary constructed by a committee under Aubrey Lewis' chairmanship. That glossary, (General Register Office, 1968) constituted the basis of the WHO Glossary for use in conjunction with ICD-8 that appeared six years later, the fruits of another Working Group chaired by Aubrey Lewis (World Health Organization, 1974). The preface to this volume acknowledged a "special debt of gratitude" to Aubrey Lewis as the WHO's principal consultant in a project which has since flowered in ICD-9 and has engendered not only the many clinical descriptions in ICD-10, but also the WHO lexicon of mental health terms (World Health Organization, 1989), which could constitute the core of a comprehensive dictionary.

\section{Further British contributions to classifications}

Parallel with these activities came the second recommendation of the Scientific Group on Mental Health Research, namely the development of standardised procedures for case finding and the assessment of severity of illness. These recommendations became the basis for a ten-year research plan in psychiatric epidemiology and social psychiatry, in which several projects closely involving British workers were conceived. One of these, 'Programme B', was concerned with the comparative study of specific mental disorders. It led to the International Pilot Study of Schizophrenia, in which the principal clinical instrument was the Present State Examination, a structured interview developed by Professor Wing and his colleagues in the UK that had been the bedrock of the US-UK project directed by Professors Cooper and Kendell (Cooper et al, 1972).

In the long term, however, a set of still more influential activities were associated with 'Programme A', 
which was focused on the standardisation of psychiatric diagnosis, classification and mental health statistics. The underlying assumption of this programme was that the objectives should be achieved by experimental inquiry rather than discussion. To this end, a series of annual seminars were organised to examine the logical basis of the classificatory process by means of diagnostic exercises. The model for these seminars, conceived and organised by British workers, concentrated on the schizophrenias and made use of videotapes, then a novel technique employed for the first time for this purpose (Shepherd et al, 1968). It quickly became apparent that the major source of variation among experienced clinicians was the difference between their nosological schemata, all of which were subject to influence by the various schools of psychiatry. It also emerged that some form of multi-dimensional system of classification would be required, and with the help of Professors Rutter and Shaffer, the WHO organised the first trial of a triaxial system for childhood disorders to demonstrate its potential value (Rutter et al, 1975).

Perhaps the most striking effect of 'Programme A', however, was its educational function. Even the most experienced and authoritarian clinicians were made aware of the ways in which their personal biases affected their own diagnostic habits. The participant experience proved both instructive and chastening, and served as an effective antidote to solipsistic dogmatism. The use of the method spread rapidly throughout the world and proved a potent means of publicising the importance of diagnosis and classification, not least to the USA. It is worth noting that initially there was no American psychiatrist participating in Programme A, so little interest was there in these issues at the time. The development of DSM-III was partly a response to this programme and to the findings of the US-UK Diagnostic Project.

\section{Conclusions}

A glance at the acknowledgements section of the draft of ICD-10 reveals how many British workers have participated in the hard grind necessary for the completion of so ambitious a project. As to content, the particular British contribution to ICD-10 is surely the emphasis placed on primary care psychiatry. The WHO's simplified scheme of classification for use in primary health care acknowledges the growing importance of this topic, which originated in work first carried out in the UK 30 years ago (Shepherd et al, 1966; World Health Organization, 1973).
In summary, then, I would suggest that much of the British contribution to the development of ICD-10 can be traced back to work carried out in ICD-8 and 9 and reflects the absence of a rigid, national system of nosology. Unfettered by chauvinistic considerations, the British nosologists were well placed to grasp the importance of reliable diagnostic agreement as a means of international communication, and were prepared to engage in the practical steps necessary to implement that view. The need to take account of mental disorders at the level of primary care in the taxonomic schema represents an extension of this approach. The work as a whole endorses the belief that a common language, a psychiatric Esperanto, constitutes no more than a necessary prerequisite for a rationally-based nosology. The grammar and syntax of the language will now be provided by ICD-10, and we must all hope that improved communication will generate progress in the diagnosis and management of mental disorders in the years to come. The proof of the pudding, however, will be in the eating, not the talking.

\section{References}

Cooper, J. E., Kendell, R. E., Gurland, B. J., et al (1972) Maudsley Monograph No. 20. Oxford: Oxford University Press. General Register Office (1968) Studies on Medical and Population Subjects, No. 22. London: HMSO.

Kendell, R. E. (1985) The contributions of British psychiatry. In Mental Disorders, Alcohol- and Drug-related Problems: International Perspectives on their Diagnosis and Classification, pp. 24-28. Amsterdam: Excerpta Medica.

KerR, A. \& MCClelland, H. (1991) (eds) Concepts of Mental Disorder. London: Gaskell.

LEwIS, A. (1961) Great Britain. In Contemporary European Psychiatry (ed. L. Bellak), pp. 145-183. New York: Grove Press. Maudsley, H. (1879) Pathology of the Mind (3rd edn). London: Kegan Paul, Trench \& Co.

Meyer, A. (1933) British influences in psychiatry and mental hygiene. Journal of Mental Science, 79, 435-463.

Rutter, M., ShafFer, D. \& ShePherd, M. (1975) A Multi-axial Classification of Child Psychiatric Disorders. Geneva: WHO.

Shepherd, M., COOPER, B., Brown, A. C., et al (1966) Psychiatric Illness in General Practice. Oxford: Oxford University Press. -, Brooke, E. M., Cooper, J. E., et al (1968) An experimental approach to psychiatric diagnosis. Acta Psychiatrica Scandinavica (supplement 201).

STENGEL, E. (1959) Classification of mental disorders. Bulletin of the World Health Organization, 21, 601-633.

World Health Organization (1973) Report of Working Group: Psychiatry and Primary Medical Care. Copenhagen: WHO.

(1974) Glossary of Mental Disorders and Guide to their Classification. Geneva: WHO.

(1989) Lexicon of Psychiatric and Mental Health Terms, Vol. 1. Geneva: WHO.

(1992) The ICD-10 Classification of Mental and Behavioural Disorders. Geneva: WHO.

Michael Shepherd, CBE, FRCPsych, Institute of Psychiatry, De Crespigny Park, Denmark Hill, London SE5 8AF 